\title{
Sandro Caparrini How Should We Study the Nexus of David Speiser Architecture and Mathematics
}

Sandro Caparrini and David Speiser critique the 1996 paper of John Clagett on "Transformational Geometry and the Central European Baroque Church" in order to shed light on how to study the Nexus of Architecture and Mathematics.

\begin{abstract}
Editor's note
While preparing the Call for Papers for the sixth Nexus conference on architecture and mathematics, I examined the Nexus archives to verify, within Nexus, what subjects had been discussed at length and what was missing. It became clear from this examination that Nexus contributions contain not only a wide variety of subject matter, but a wide variety of methods of study as well. In order to try begin a dialogue about methodology (a topic that was touched on during the Round Table discussion at Nexus 2000 in Ferrara), I solicited comments from two scholars in different fields on the paper presented at the first Nexus conference in Fucechio in 1996 by John Clagett entitled "Transformational Geometry and the Central European Baroque Church.” Dr. David Speiser, physicist, who has followed Nexus since its inception, and Dr. Sandro Caparrini, historian of mathematics and newcomer to Nexus, bring not only different disciplinary points of view to the subject but have different experiences of the Nexus community. The polemic that follows is in no way intended as a personal criticism of Clagett, but rather a discussion of method and the degree of rigor that should be expected from Nexus contributions. Further comments from readers of the Nexus Network Journal who wish to contribute to this dialogue are welcome. Kim Williams.
\end{abstract}

\section{SANDRO CAPARRINI WROTE:}

The subject of the article is truly a particular one. Clagett proposes to find the relationships between the architecture of the Baroque churches of Central Europe and "transformational geometry". It should be noted that Clagett does not seek generic links between the Baroque and mathematics, but between a certain type of Baroque and a particular branch of geometry. There is no doubt that there are in some way connections between some aspects of Baroque architecture and the mathematics of that time: Guarini was a mathematician; Wren was a mathematical physicist of some renown; Desargues discovered projective geometry as a result of his work as an architect. However, it seems to me that Clagett's paper discusses significant problems without taking the first step towards their resolution.

It would be necessary to review the paper line by line in order to give substance to this criticism. I think however that it can be briefly summed up in two points:

1. Clagett cites precise mathematical theories while using a language that is incredibly vague. This leads him often into error, as when, for example, he confuses different theories.

Let us look at some examples. What exactly is meant by the statement, "during this time, reasoning shifted from the isolated to the integrated" (p. 38)? Almost nothing; it is a statement that could be applied to any scientific theory that assembles and corrects knowledge that was previously scattered. The phrase, “in Newton's Principia (1687) the phenomena of dynamics was [sic] so lucidly formulated that the physical world was redefined through motion" (p. 38) demonstrates that Clagett has only second-hand knowledge of the Principia, since in that treatise 
the results are expressed in a difficult, concise, obscure way, a far cry from the clarity of modern manuals and almost impossible for readers of the time to comprehend (and, for that matter, for readers of our own day as well).

The truly troubling point, central to the discourse as a whole, comes when the paper deals with "transformational geometry". In the history of mathematics, the theory of transformation is a precise point of view that goes back to the second half of the $1800 \mathrm{~s}$, and whose general formulation was first given by Felix Klein in 1872. Citing Euclid's demonstration of the Pythagorean theorem in this context shows that Clagett has a weak grasp of the material. There is no doubt that he intends a reference to the theory of groups of transformation, since he talks constantly of rotations, translations, reflections, and other transformations of the plane.

Besides being vague, Clagett's style is often contorted. A sentence such as "This effect of oscillating proximity resulted from an intention to create a spectrum of elements eternally approaching singularity; to establish a dynamic continuum" (p. 38) subjects the reader to a couple of minutes of mental torture before he is able to extract some hint of meaning. Here the use of scientific terms ("oscillating", "spectrum", "singularity", "dynamic continuum") is superimposed on a language worthy of the worst art critic. Barba non facit philosophum; a few technical terms are not sufficient to demonstrate that one knows mathematics. The term "approaching singularity" must hold a special fascination for Clagett, because he returns to it at the article's end (p. 50). By closing one's eyes and concentrating a bit it is almost possible to visualize this "approaching singularity"; it is an image worthy of Poe or Kafka.

2. The connection between mathematical developments and architectural innovations are never proven in any way, shape, or form. There are no citations of notes, letters, or other writings that make evident these connections. In effect, Clagett limits himself to setting two arguments, the mathematical and the architectural, side-by-side, without making them interact in any way. Thus, it becomes possible to prove anything one wished, and in fact, this method is often used in texts of scant scientific value, such as specious New Age works that "demonstrate", for instance, that the Maya and the Egyptians were in contact (both cultures built pyramids).

Let us take an example. Close to the beginning of the article is set forth a table which, according to Clagett, serves to place the Central European Baroque church in the context of the mathematical development of the seventeenth and eighteenth centuries (Table 1).

What can be deduced from this table? Absolutely nothing. There is no relation whatsoever between the Methodus incrementorum of B. Taylor (1715) and the churches of C. Dietzenhofer. Effectively a table such as this could prove a thesis that is the exact opposite of Clagett's: there are no relationships at all between Baroque architecture and mathematics; the two disciplines appear as far from each other as the works of Shakespeare and the development of statistics.

If Clagett wished to demonstrate, for example, that a given architect of the 1600 s was influenced by the Pantheon, no proof would be necessary beyond stylistic resemblances. The importance and notoriety of the model would be in itself sufficient proof. The situation changes when it is necessary to demonstrate that a given architect took as his point of departure the most abstract mathematics of his day: in this case it is necessary to find direct connections. Are there letters in which the architect in question declares that he has read a certain book? Do we know if he was actively engaged in mathematics, or if he was in contact with mathematicians? In the case of Thomas Jefferson, for example, it is known that he had in his library various texts of higher mathematics. If we were to find in Monticello specific geometric coincidences then we would be

8 SANDRO CAPARRINI AND DAVID SPEISER - How Should We Study the Nexus of Architecture and Mathematics? 
justified in deducing that these are not chance occurrences. These are the methods with which history is written.

\begin{tabular}{|c|c|c|}
\hline Desargues: Brouillon projet & 1639 & \\
\hline Descartes: La Géometrie & 1673 & \\
\hline \multirow[t]{4}{*}{ Leibniz's first paper on the calculus } & 1684 & $\begin{array}{l}\text { G. Dientzenhofer: Pilgrimage church at } \\
\text { Kappel begins construction }\end{array}$ \\
\hline & 1687 & $\begin{array}{l}\text { Approximate start of the Central } \\
\text { European Baroque church }\end{array}$ \\
\hline & 1694 & $\begin{array}{l}\text { Fischer v. Erlach: Project for } \\
\text { Dreifaltigkeitskirche }\end{array}$ \\
\hline & 1713 & C. Dientzenhofer: Smirice, chapel \\
\hline \multirow[t]{2}{*}{ Taylor: Methodus incrementorum } & 1715 & \\
\hline & 1726 & J. Dientzenhofer: Holzkirchen \\
\hline \multirow[t]{2}{*}{ Saccheri: Euclid Vindicatea } & 1733 & Neumann: Würzburg, Hofkirche \\
\hline & 1737 & Guarini: Architettura civile \\
\hline \multirow[t]{2}{*}{ D’Alembert: Traité de dynamique } & 1743 & \\
\hline & 1744 & J.M. Fischer: St. Michaelskirche \\
\hline \multirow[t]{2}{*}{ Euler: Introductio } & 1748 & \\
\hline & 1763 & Neumann: Vierzehnheiligen \\
\hline John Love: Geodesia & 1768 & \\
\hline Hyperbolic trigonometry & 1770 & $\begin{array}{l}\text { Approximate close of the Central } \\
\text { European Baroque church }\end{array}$ \\
\hline Lobachevskian geometry & 1827 & \\
\hline
\end{tabular}

I don't see any particular signs of the influence of higher mathematics in the architecture that is discussed by Clagett. He speculates, for example, that the attempt to make squares and circles coincide derives from the problem of the quadrature of the circle (p. 41). In reality, there are no necessary connections between these two forms: every high school student can draw circles in squares and squares in circles without wanting to prove any theorem by doing so. More generally, the use of circles, squares, and ellipses arranged in various ways doesn't indicate a knowledge of higher mathematics. It is obvious that particular symmetries exist in Baroque architecture: a good portion of art has to do with symmetry (or its absence). There are certainly examples of figures that are rotated or deformed in Baroque decoration, derived almost certainly from the artist's need to give movement and variety to architecture elements used thousands of times before. Is it possible to see how this phenomenon is connected to Descartes's Géométrie of 1637 of or to Desargues's Brouillon projet of 1639?

A last note on Clagett's weak thesis is shown on p. 49, on which is discussed the influence of Desargues's projective geometry on architecture. The works cited go from 1580 to 1766, and thus show how Clagett confounds the study of perspective, which goes back at least as far as Masaccio, with the mathematic discipline known as projective geometry (and perhaps the descriptive geometry of G. Monge as well). Those who wish to know the details on the diffusion of perspective and the methods used to study it should consult The Science of Art: Optical Themes 
in Western Art From Brunelleschi to Seurat by Martin Kemp (1990). It is a work rich in precise facts, that shows how a paper of this type should be written.

As the above arguments show, my critique concentrates on two principle points, and this makes Clagett's ideas appear to be better defined than they actually are. In fact they are often so imprecise that it is difficult to analyze them. This is in fact the main weakness of the paper: it is not possible to say that Clagett has given even the slightest demonstration of a possible connection between Baroque architecture and advanced mathematics.

\section{DAVID SPEISER REPLIED:}

Kim Williams, the Spiritus Rector of the Nexus conferences, had told me that John Clagett's paper on the "Transformational Geometry and the Central European Baroque Church", published in the first book, Nexus: Architecture and Mathematics (1996), had been criticised by Sandro Caparrini. As I myself had retained a good impression of this contribution, which I had found stimulating at the Nexus 1996 conference in Fuccechio, I expressed my surprise. Upon reading Caparrini's critique and then twice re-reading Clagett's article, I had to admit that Caparrini's critique, as far as it goes, is justified. But I think that he does not sufficiently take into account that the Baroque is a style particularly difficult to investigate and to analyze, especially from the Nexus Architecture-Mathematics point of view.

And furthermore, I say, one has to take into account that while, due to the lack of precise mathematical notions, Clagett's views are not solidly enough grounded in the architecture side of the Nexus, his remarks, nevertheless, seem to me stimulating for further research, and to point in fruitful and promising directions. Whereupon the Spiritus Rector invited me to write a short summary of my ideas. In what follows, I review by referring to a few examples of some of Clagett's views, appreciating and criticising them, but always from the Nexus Architecture-Mathematics point of view. For this reason and for not being too boringly repetitious, I refer to the two pillars of Nexus simply by the letters A and $M$.

One must consider, that most, if not all, concrete AM confrontations-and the same holds even more so for the really established AM connections-refer to either Greek, Roman, Romanesque, or Renaissance buildings, and sometimes also to modern ones. But rarely has there been a penetrating AM study of a Gothic or a Baroque building, especially of one that presents most of the characteristics of either of these two styles. The reason for this is obviously that the Gothic e and the Baroque styles present a more complex and difficult situation for AM research. Therefore AM investigations on either of these styles must always be considered as pioneer work; assertions in a direction that promise to be fruitful are meritorious, and in spite of their shortcomings and the criticism they deserve, must be welcomed by students of the Nexus-AM. And indeed, among the numerous points made by John Clagett, there are many that do point in a possibly fruitful direction for further research, and may even guide future studies to something more.

In the following I shall discuss a few examples.

- Baroque architects often tried to hide the geometric calculus, which underlies the plan of a building already before the details are worked out. This, I guess, was a reaction to the ideal of clarity and transparency that guided the great Renaissance artists. And this is probably what Clagett has in mind, when he says "Yet Neumann's section.... ; as if Neumann once again shifted the layers of the chapels plan" (pp. 45-46). This deliberate

10 SANDRo CAPARRINI AND DAVID SPEISER - How Should We Study the Nexus of Architecture and Mathematics? 
hiding of the basic geometric idea is one reason that makes it so difficult to grasp the "geometric calculus" behind Baroque buildings.

- But then Clagett also points to another important characteristic of the Baroque style, e.g., "the intersection of geometric curves, surfaces, and figures, such as circles, squares, octagons, cupolas, etc.” (p. 45). In the Romanesque and Renaissance styles, these geometric figures are presented as beautiful in themselves, each one contributing individually to the desired beauty and harmony of the building. But Baroque architecture is not satisfied by this "individual presentation," favouring M-constructions of "interpenetrating" curves, surfaces and 3-dimensional bodies, all chosen from a great variety. It is through the well-thought-out interplay of these M-elements that the architect expresses his ideas. This is an important point, even if Clagett does not sufficiently analyse the mathematics used in each case. However, for a student it is a useful starting point for penetrating into the puzzles presented by the Baroque style.

- The same must be said about his " five intersecting quasi-ellipsoidal domes" (p. 45), also something deeply characteristic for the Baroque style, where A makes quite important use of M. But then, what exactly is "quasi-ellipsoidal" ? After his conference I had myself a very interesting conversation with Clagett, during which he told me that the presumed ellipses observed in architecture are often in fact "ovals". Ovals, contrary to ellipses, are not curves defined by one law only, but are put together from several arcs of circles in a "smooth" way such that the tangent to the curve never changes abruptly, but always continuously: an oval has no corners.

But when much later I showed Sylvie Duvernoy's very interesting paper on arenas from the Nexus 2002 conference in Obidos, "Architecture and Mathematics in Roman Amphitheaters" to my friend, mathematician B. Marzetta, he discovered and proved that any ellipse can be approximated as closely as one wishes by an oval and vice versa. This, of course, puts many often-made statements, whether on the Roman or the Baroque style, into question! Whether for 3-dimensional ellipsoids an analogue statement holds, i.e., whether there are "ovaloids", I do not know. A three-dimensional ovaloid could be generated through the rotation of an ordinary two-dimensional oval around its major axis of symmetry. Cutting this ovaloid in two by means of a horizontal plane of symmetry, the upper part may serve as the cover of a Baroque church. A possible candidate for this, among many others, is Borromini's S. Carlo alle Quattro Fontane in Rome.

This situation presents a series of interesting questions and problems for Nexus research, which range from measurement techniques, through stylistic investigations of historic buildings, up to aesthetic theories on Baroque art.

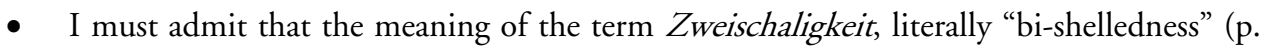
48), borrowed from the German, did not become clear to me; neither did I understand to what exactly in the building it refers, nor what in general its aim and function in Baroque architecture are.

- Clagett uses explicitly the term Gesamtkunstwerk ( p. 37), which was coined by R. Wagner, who introduced it into his theory of the Musikdrama. Here Clagett makes a very fortunate point. That the Baroque style artistically combined architecture, sculpture, painting, and especially the art of decoration to a degree not ever seen in Europe before 
or since, was, of course often noted. But I wonder, whether the full importance of the ambition of the Baroque Gesamtkunstwerk was always grasped sufficiently and seriously enough. For here we probably find the highest ambition of the Baroque art, and this too is an open field for all kinds of Nexus research.

- It is curious that Clagett does not mention at all the "artificial architectures" created in so many Baroque churches and palaces, together with the sister-art painting, and, of course, also with the sister-art M, namely, the understanding of the rules of perspective. This heralds a first, of course only intuitive, understanding of projective geometry. The first example of such an artificial architecture, extending and covering the built one, may be Michelangelo's ceiling of the Sistine Chapel, and the most virtuoso performance is probably Pozzo's ceiling in San Ignazio in Rome. Later we find, of course, many such painted extensions in Austrian and South German churches and palaces as well. Incidentally, when one manages to see and appreciate the built and the painted architecture as one single building, one realizes that one criticism often made of Baroque art is unjust: Baroque decorations, which are often felt to be overloaded and even bombastic, will be appreciated according to their just value if one realizes that they belong to one building only, which is, however, about twice as high as the purely architectural structure!

These examples shows, I think, where the merits of Clagett's stimulating conference as well as its weaknesses lie. He points to quite a few, important characteristics of Baroque architecture and style, and they are a good starting point for Nexus reflections as well as for concrete AM research, but indeed, much remains to be done! For, unfortunately, and this holds especially for the end of the article, the respective roles of $A$ and especially $M$ as well as their meeting points, i.e., the Nexus, are not precisely enough analyzed and worked out. While he leads our attention to many an interesting question, his somewhat cavalier attitude to mathematical vocabulary and theorems, often suggest to the reader another answer to it.

\section{About the Authors}

Sandro Caparrini was born in Rapallo (Genoa) in 1963, and resides near Turin. He holds degrees in physics and mathematics. He is a historian of mathematics, with a special interest in the history of mechanics. He was recently awarded, for his essay entitled "Early Theories of Vectors," the 2003 Slade Prize of the British Society for the History of Science, presented biennially to the writer of an essay that makes a critical contribution to the history of science.

David Speiser is Professor Emeritus at the Catholic University of Louvain, where he taught physics and mathematics from 1963 to 1990 . His research concerned elementary particles and physical mathematics. He has been giving lectures and seminars regularly at the Scuola Normale di Pisa since 1990. Since 1980, he is the general editor of the complete works of the mathematicians and physicists of the Bernoulli family. His work on the history of science includes various publications, some of which are related to art history. $\mathrm{He}$ presented "The Symmetries of the Leaning Tower and the Baptistery of Pisa" at Nexus '96, now available in Nexus: Architecture and Mathematics (1996). 